\title{
Velamentous insertion of the umbilical cord in monochorionic triplet pregnancy: life- saving condition?
}

\author{
Liangcheng Wang, ${ }^{\oplus}$ Isao Horiuchi, Tomoyuki Kuwata, Kenjiro Takagi
}

Obstetrics and Gynecology, Saitama Medical Center, Jichi Medical University, Saitama-shi, Japan

\section{Correspondence to} Dr Liangcheng Wang, kkscsc@gmail.com

Accepted 16 April 2019

\section{DESCRIPTION}

A 26-year-old gravida 2 para 1 woman had a monochorionic-triamniotic (MT) triplet pregnancy that was eventually terminated by emergency caesarean section at week 31 of gestation owing to rapid changes in cervical length. She was referred to our hospital at week 9, and a diagnosis of MT triplet pregnancy was confirmed (figure 1A). Ultrasonography at week 13 revealed marginal insertion of the cord in one fetus (figure 1B) and velamentous insertion in another (figure 1C). She was admitted to our hospital in week 25 owing to the threat of preterm labour. Prenatal ultrasound assessment showed the amniotic volumes were normal in all three sacs; no obvious discordance despite suspected small for gestational ages. Fetal bladders were filling regularly in the three fetuses; predelivery umbilical artery resistance indexes were within the normal range. The body weights of the three infants were 1230, 1254 and $1400 \mathrm{~g}$. The Apgar score at 1 and $5 \mathrm{~min}$ were $7 / 8,8 / 9$ and $8 / 9$; the $\mathrm{pH}$ of the umbilical vein were 7.29, 7.28 and 7.29; the haemoglobin concentrations were $155 \mathrm{~g} / \mathrm{L}, 163 \mathrm{~g} / \mathrm{L}$ and $173 \mathrm{~g} / \mathrm{L}$, respectively. Grossly, the common placenta was visibly divided into three equal parts by amniotic membranes

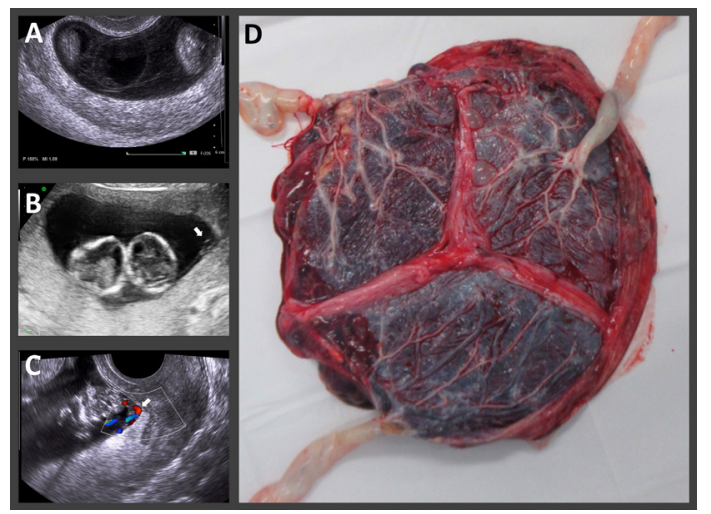

Figure 1 (A) A monochorionic-triamniotic triplet pregnancy diagnosed at week 9 of gestation. (B) Marginal insertion of the cord was observed in one fetus via transabdominal ultrasound, and (C) velamentous insertion of the cord was observed in another fetus via transvaginal ultrasound at week 13 of gestation. (D) Gross view of the placenta. The placenta was visibly divided into three equal parts by amniotic membranes with an appearance similar to a Mercedes-Benz logo. Marginal insertion in one fetus and velamentous insertion of the umbilical cord in another fetus were observed, which were comparable to the prenatal ultrasound findings at week 13 of gestation. with the appearance of a three-pointed star, similar to a Mercedes-Benz logo (figure 1D). One cord was attached to the middle of the shared placenta, and the other two revealed marginal insertion and velamentous insertion of the cords, which were comparable to the prenatal ultrasound findings at week 13.

Fetal loss, twin-to-twin transfusion syndrome (TTTS) and discordance are the most common complications in monochorionic twin pregnancies. Marginal/velamentous cord insertions that are frequently observed in monochorionic twin pregnancies have been recognised as a potential risk factor for adverse perinatal outcome. ${ }^{12}$ Why did all three fetuses in the present case survive without any complications? We observed that a combination of normal, marginal and velamentous cord insertions in a monochorionic triplet pregnancy appeared to be ideal, with the advantage of increasing the distance of the cord insertion sites from each other. Does it mean that marginal and velamentous cord insertions contribute to the absence of TTTS? Can marginal/velamentous cord insertions in monochorionic triplet pregnancy play a role in reducing the risk of lethal vascular anastomoses since early gestation? Or it is just an exceptional case? We cannot base our conclusions on a single rare case. Further studies analysing the relations are warranted.

\section{Learning points}

- Marginal/velamentous cord insertion that is frequently observed in monochorionic twin pregnancies has been recognised as a potential risk factor for adverse perinatal outcome. However, its role in triplet pregnancy is unclear.

- We present a rare case of monochorionic triplet pregnancy in which abnormal cord insertions may have possibly contributed to the absence of lethal vascular anastomoses. Further studies analysing the relations are warranted.

Contributors LW wrote the manuscript and signed the consent form. All authors were involved in the management of the patient.

Funding The authors have not declared a specific grant for this research from any funding agency in the public, commercial or not-for-profit sectors.

Competing interests None declared.

Patient consent for publication Obtained.

Provenance and peer review Not commissioned; externally peer reviewed. 


\section{Images in...}

\section{REFERENCES}

1 Kalafat E, Thilaganathan B, Papageorghiou A, et al. Significance of placental cord insertion site in twin pregnancy. Ultrasound Obstet Gynecol 2018;52:378-84.

2 Couck I, Mourad Tawfic N, Deprest J, et al. Does site of cord insertion increase risk of adverse outcome, twin-to-twin transfusion syndrome and discordant growth in monochorionic twin pregnancy? Ultrasound Obstet Gynecol 2018;52:385-9.

Copyright 2019 BMJ Publishing Group. All rights reserved. For permission to reuse any of this content visit https://www.bmj.com/company/products-services/rights-and-licensing/permissions/

BMJ Case Report Fellows may re-use this article for personal use and teaching without any further permission.

Become a Fellow of BMJ Case Reports today and you can:

- Submit as many cases as you like

- Enjoy fast sympathetic peer review and rapid publication of accepted articles

- Access all the published articles

Re-use any of the published material for personal use and teaching without further permission

For information on Institutional Fellowships contact consortiasales@bmjgroup.com

Visit casereports.bmj.com for more articles like this and to become a Fellow 